\title{
Optimization of Volume of Inflow in Bypass Pipeline adjoining a Long Open Channel
}

\author{
Noriaki Takeda ${ }^{1}$ and Hitone Inagaki ${ }^{2}$
}

\begin{abstract}
The development of a system capable of distributing water, without shortages or surpluses, to each terminal in a down-stream region is a topic of interest in the context of open channel waterway systems, in which the water demand for agriculture fluctuates considerably. In this study, the optimal combination of inflow amount to the upstream side of the check gate of the main open channel from the pipeline was attempted to be determined for a double-waterway system, in which the pipeline is constructed along the main canal of the long open channel. A type of conjugate gradient method called the Davidon-Fletcher-Powell method was embedded into an unsteady flow program for the open channel, and four types of evaluation functions for water diversion and water level, which incorporate a penalty function corresponding to surplus water and volume of inflow, were introduced to evaluate the degree of achievement with respect to the objective. The effectiveness of the evaluation function was investigated, and the results demonstrated that the inflow stabilized in the order of water diversion $<$ water level $<$ water level + water diversion $<$ water level + surplus water; irrespectively, a favorable result was obtained from each of the evaluation functions. Therefore, the doublewaterway system is an ideal system in which the open channel and the pipeline mutually overcome the limitations of each other, and the system is capable of managing the demand fluctuation at the terminals.
\end{abstract}

Keywords: Long open channel; Pipeline; Doubled-waterway system; Davidon-Fletcher-Powell (DFP) method; Evaluation function; Penalty function

\section{Introduction}

A large irrigation canal features a large transportation distance and consists of a facility involving a free water surface composed of an open channel, a tunnel, a culvert, and a siphon. To ensure adequate water supply, the waterway is suitable for a large volume of water flow with little variation, owing to the large amount of time required for the water to reach its destination. In several districts in Japan, long, open channel-type main canals were built along with the development of water sources during the period of increasing food production from the mid-1940s to the early 1970s (Showa 20-40s).

However, the shift of farmers to part-time farming, advanced aging among farmers, a lack of successors, and a conversion from rice to field crops have led to the use of pipelines for branch channels to reduce the labor required in water management strategies for rice paddies. As a result, the system has evolved into a composite waterway system, in which the long main canal is of the supply-oriented type whereas the channels from the branching points to the terminals are demand-oriented type pipelines.

From the perspective of water use, the approach to irrigation has also shifted from conventional surface irrigation to a form of irrigation in which the demand is concentrated during the day. Because the flow fluctuates owing to the demand-oriented branch channel pipeline and its impact accumulates on the main canal, this concentration of demand

\footnotetext{
${ }^{1}$ Postgraduate Student, Interdisciplinary Graduate School of Agriculture and Engineering, University of Miyazaki, 1-1 Gakuen Kibanadai-nishi, Miyazaki 889-2192, Japan

${ }^{2}$ Professor, Faculty of Agriculture, University of Miyazaki, 1-1 Gakuen Kibanadai-nishi, Miyazaki 889-2192, Japan (Corresponding Author) Email: a03221u@cc.miyazaki-u.ac.jp
}

leads to limitations in supplying the appropriate water volume to the main canal system, such as reduction in the water level, inability to provide an appropriate level of distribution, and occurrence of surplus water.

In a long system in which the branch channels diverge in a dendritic manner from the main canal, a supply-driven open channel is used for the main waterway and demanddriven pipelines are used for the branch channels. To overcome the limitations pertaining to the gap in the demand volume, technical solutions are still under development through trials and errors.

For instance, the agricultural section that extends for 31 $\mathrm{km}$ in the downstream area of the Aichi waterway of the Aichi Irrigation Phase I Project (built between 1955 and 1961 ) is an open channel system in which the upstream water level control gates are connected in series; however, owing to the daily fluctuations, there is a limit to the extent in which water delivery management alone can address the issue of water delivery (Takeda and Inagaki, 2019). The current approach of the Aichi Irrigation Phase II Project (built between 1981 and 2004) involves utilizing the water storage in the canal by using gates for controlling the water level in both the upstream and downstream regions, and mismatches in the supply and demand can be adjusted by operating the check gate and using the storage within the canal (Takeda and Inagaki, 2018).

As with the case of the eastern main canal extending for approximately $76 \mathrm{~km}$ in the Toyokawa waterway, longer open channels mean that the water takes a longer time to reach its destination; in such a scenario, water delivery management and improvements in check gate functions can no longer address the issues. As a result, the level of water shortage for water distribution increases (Takeda and Inagaki, 
2019).

Therefore, an approach for stabilizing the stream regime of the main canal and minimizing the deficits and surpluses in the volume of water supplied is being sought after for current systems involving a long open channel main canal and branch channel pipelines. One plausible measure for this is to stabilize the stream regime of the long main canal by installing a parallel pipeline for the existing open channel and instantly supplying water from the upstream to the downstream region. Furthermore, agricultural irrigation sections in the downstream area of the Aichi waterway use an open channel waterway system to pass water strictly for agriculture, which involves considerable fluctuation in the demand; however, there is a need for the development of a system capable of distributing water to every terminal without shortages or surpluses.

To this end, in this study, considering an agricultural section in the downstream area of the Aichi waterway, a numerical model was developed to investigate the position in which water flows from an adjoining pipeline into the main open channel, and to study the volume of the inflow for a doublewaterway system in which a pipeline is built alongside the long open channel main canal. A type of conjugate gradient method called the Davidon-Fletcher-Powell (DFP) method was embedded into an unsteady flow program for the open channel. In addition, four types of evaluation indices that incorporate penalty functions on the surplus water and volume of inflow and an evaluation function for the best fit of the water diversion and water level were introduced to evaluate the degree of achievement with respect to the objective.

\section{Hydraulic analysis model for an open channel}

\subsection{Overview of the model for an open channel facility}

The considered exclusively agricultural water section is a $29 \mathrm{~km}$-long open channel with a trapezoidal cross-section and a mean gradient of 1/3700; further, 11 upstream water level check gates are installed across the channel. The most upstream gate is a manually operated Kitaike check gate. On the Aichi Irrigation Phase I Project, 10 gates (except the most downstream Mihama check) are AMIL-type gates that control the upstream water level. Mihama check is not an AMILtype gate but a spillway of a fixed overflow weir.

Water passing through the channel flows through the upstream section at $9.0 \mathrm{~m}^{3} / \mathrm{s}$ during the Phase I period, and the flow decreases to $6.5 \mathrm{~m}^{3} / \mathrm{s}$ during the Phase II period; a similar decrease can also be observed downstream.

The specifications for the main canal and irrigation planning as well as the numerical model for an AMIL gate are discussed in a previous report (Takeda and Inagaki, 2019).

From the starting point at Sakurakane to the end point at Mihama, the main canal, which extends approximately 29 $\mathrm{km}$, is divided into 554 mesh elements; the model calculates the water level at even-numbered points and the flow velocity at odd-numbered points. Figure 1 shows the hydraulic longitudinal section, Table 1 presents the controlled water levels at the AMIL check gates and their corresponding mesh numbers, and Table 2 lists the controlled water levels at the spillways and the corresponding mesh numbers.
Table 1: $\quad$ Specifications for AMIL gates

\begin{tabular}{|c|c|c|c|c|c|c|}
\hline \multirow{3}{*}{ Mesh } & \multirow{3}{*}{ Check Name } & \multirow{3}{*}{ Type } & \multicolumn{2}{|l|}{ Check } & \multicolumn{2}{|c|}{ Channel } \\
\hline & & & Water Level & Height & Lower Width & Upper Width \\
\hline & & & TP.m & TP.m & $\mathrm{m}$ & $\mathrm{m}$ \\
\hline 479 & Kitaike & D630 & 31.42 & 28.62 & 3.55 & 6.70 \\
\hline 437 & Handa & D630 & 30.97 & 28.17 & 3.55 & 6.70 \\
\hline 385 & Narawa & D630 & 29.99 & 27.19 & 3.55 & 6.70 \\
\hline 331 & Itayama & D630 & 29.00 & 26.20 & 3.55 & 6.70 \\
\hline 273 & Hinohara & D355 & 28.13 & 26.53 & 2.00 & 3.75 \\
\hline 193 & Owaki & D500 & 27.11 & 24.87 & 2.80 & 5.30 \\
\hline 143 & Unoike & D315 & 26.02 & 24.62 & 1.80 & 3.35 \\
\hline 107 & Sugekari & D400 & 25.47 & 23.67 & 2.24 & 4.25 \\
\hline 63 & Kowa & D160 & 24.62 & 23.91 & 0.90 & 1.70 \\
\hline 27 & Uchiumi & D400 & 24.17 & 22.37 & 2.24 & 4.25 \\
\hline
\end{tabular}

Table 2: Specifications for the spillway

\begin{tabular}{|c|c|c|c|}
\hline Mesh & Name & $\begin{array}{c}\text { Set water Level } \\
\text { Bulkhead elevation } \\
\text { TP.m }\end{array}$ & Structure \\
\hline 480 & Kitaike spillway & 31.57 & AMIL Gate \\
\hline 274 & Hinohara spillway & 28.28 & $"$ \\
\hline 144 & Unoike spillway & 26.24 & $"$ \\
\hline 66 & Kowa spillway & 24.77 & $"$ \\
\hline 4 & Mihama spillway & 23.66 & Fixed Weir \\
\hline
\end{tabular}

\subsection{Numerical model for unsteady flow in the open channel}

The flow speed and pressure of the one-dimensional unsteady flow in the open channel were calculated using the central-difference scheme (Shiraishi, 1969), employing the equation of motion and equation of continuity. The Manning formula was used to estimate the friction loss. The equation of motion for the constant direction of the open channel can be expressed as equation (1), and the equation of continuity can be expressed as equation (2).

$$
\frac{1}{g} \frac{\partial v}{\partial t}+\frac{1}{g} \frac{\partial}{\partial x}\left(\frac{v^{2}}{2}\right)+s+\frac{\partial h}{\partial x}+\frac{n^{2} \cdot|v|}{R^{4 / 3}} v=0
$$

where $g$ is the gravitational acceleration, $v$ is the flow speed, $s$ is the gradient of the waterway, $h$ is the water depth, $R$ is the hydraulic radius, $n$ is the coefficient of roughness, $x$ is the distance, and $t$ is the time.

$$
\frac{\partial A}{\partial t}+\frac{\partial Q}{\partial x}=q
$$

where $A$ is the cross-sectional flow area, $Q$ is the flow rate, and $q$ is the lateral inflow.

The water supply, water diversion, and volume of inflow from the Sakurakane check point $(\mathrm{CH})$ at the most upstream region were treated as corresponding to lateral inflow.

In the process of solving the equation of motion and equation of continuity of the open channel by using the centraldifference scheme, the gate flow rate was calculated by solving the equation of motion of the float mechanism at the check gate by using the numerical integral obtained using the fourth-order Runge-Kutta method (Takeda and Inagaki, 2019). 

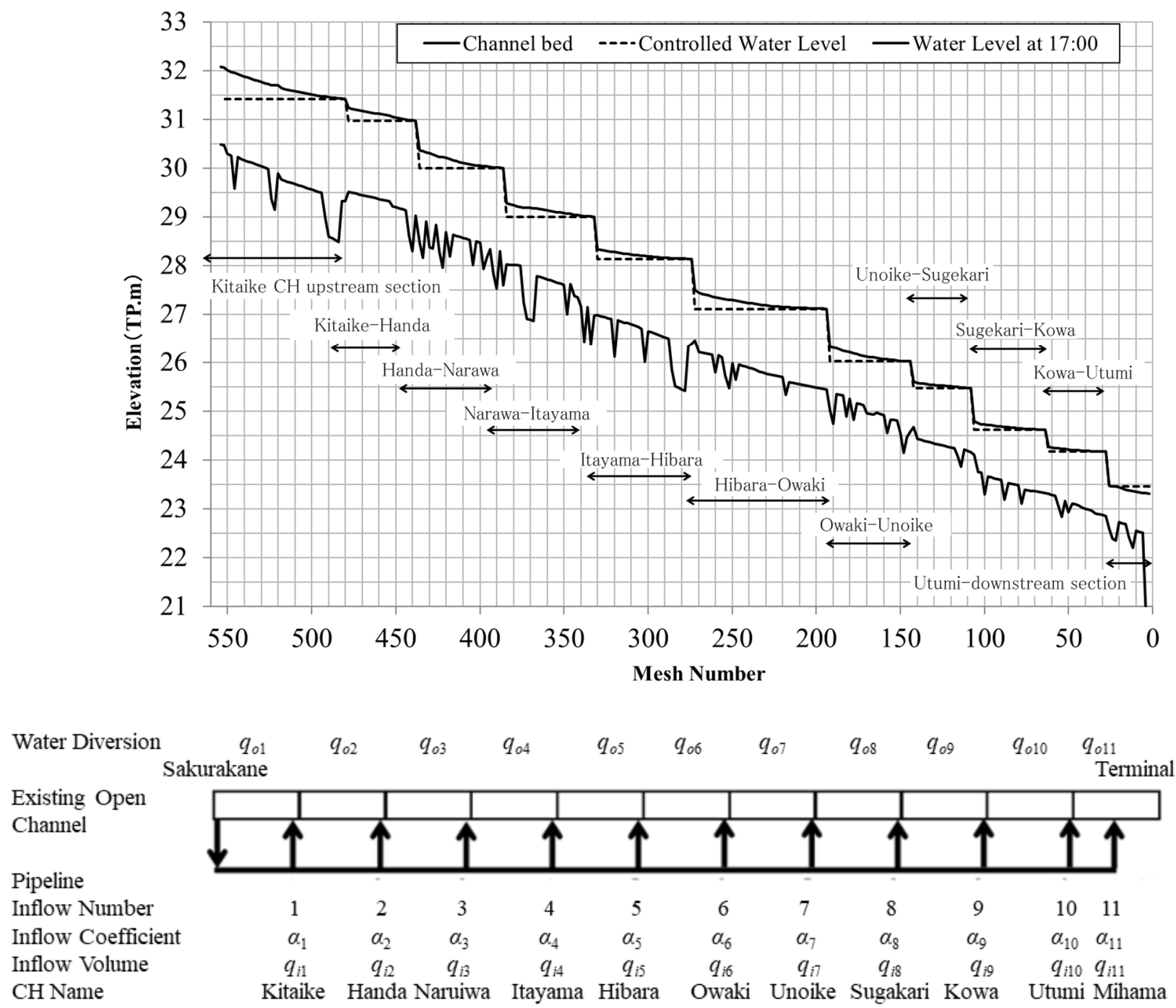

Figure 1: Longitudinal section of the double-waterway main canal and schematic for the adjoining bypass pipeline

\section{Numerical model of the inflow}

\subsection{Model for bypass pipeline and point of inflow}

As shown in Figure 1, the model for the bypass pipeline, which assumes the position and volume of the inflow (i.e., inflow model), places the new pipeline alongside the existing open channel, and branches from the open channel into a tributary at the Sakurakane $\mathrm{CH}$.

A point of inflow is designated on the upstream side of all $\mathrm{CHs}$, and the indicator for the inflow is the point in time at which the water level on the upstream side of the check falls $0.05 \mathrm{~m}$ below the controlled water level.

\subsection{Inflow model}

For the inflow model, the volume of inflow $\left(q_{i n}\right)$ is treated as $Y$ and expressed as $Y=\alpha \times X$; the diverging water per section upstream of the point of inflow $\left(q_{o n}\right)$ is treated as $X$, and this value is multiplied with an inflow coefficient $\alpha$, as shown in equation (3). Although $\alpha$ could be chosen to have a variable or constant value, in this work, a constant value $\alpha$ was selected to simplify the model.

$$
q_{\text {in }}=q_{\text {on }} \times \alpha_{n} \quad(n=1 \sim 11)
$$

Note that if it is assumed that a point of inflow cannot be provided for the check due to local conditions etc., as a countermeasure, the volume of inflow on the downstream side can be calculated by taking a sum of the diverged water in the section between the point of inflow on both the upstream and downstream sides and multiplying it with a coefficient.

The volume of the inflow is obtained by equation (4) by subtracting the volume of water diversion up to the upstream water inflow point (point $\mathrm{m}$ ) from the total volume of water diversion from point 1 to point $n$.

$$
q_{\text {in }}=Q_{o n} \times a_{n}=\left(\sum_{n=1}^{n} q_{\text {on }}-\sum_{n=1}^{m} q_{o n}\right) \times \alpha_{n}
$$

where $m$ is the position number of the water inflow point on the upstream side.

\section{Evaluation function}

\subsection{Definition of an evaluation function}

As a criterion for determining whether water delivery is 
being managed appropriately, the function $J$ was defined as the difference between the expected water diversion and calculated water diversion, and a set of coefficients ( $n$-coefficients) $\alpha_{1}, \alpha_{2}, \ldots, \alpha_{n}$ was optimized such that $J$ was minimized. The condition that minimizes $J$ is referred to as a criterion or an objective function.

To equate the computed water diversion $q_{b c}$ with the expected water diversion $q_{b o}$, the undetermined coefficients $\alpha$ are required to be searched for in a manner such that the function $J$ for evaluating the degree of difference between $q_{b c}$ and $q_{b o}$ is minimized.

In a runoff analysis model, the evaluation function $J$ uses absolute and relative criteria in order to emphasize the compatibility of the high and low parts of the hydrograph. However, since the $\chi$-squared criterion has high overall suitability and has been widely used for the determination of $J$ (Kadoya et al., 1980), this study adopted $\chi$-squared criterion to determine J (Eq.5).

The relative error $\varepsilon_{R}$ was defined as shown in equation (6).

$$
\begin{aligned}
& J=\sum\left\{\left(q_{b o i}-q_{b c i}\right)^{2} / q_{b o i}\right\} / N \\
& \varepsilon_{R}=\sum\left(\left|q_{b o i}-q_{b c i}\right| / q_{b o i}\right) / N
\end{aligned}
$$

where $N$ is the number of data points, and $i$ is the data ID.

A smaller evaluation function $J$ indicates that the computed water diversion is more similar to the expected water diversion, and the two values are equal if the function $J$ is zero.

\subsection{Indicator for best fit of the objective function}

The minimum function of the main open channel is to secure the water level necessary for water diversion, to divert the flow rate necessary for the diversion work without deficiency, and to not generate spilled water.

Therefore, the water diversion, water level, and surplus water were selected as the indices for evaluating the agreement between the calculated and the target value, considering the data availability and the degree of explanation of the basic performance of the main channel.

As for the target values, the water diversion is the planned diversion flow rate, the water level is the required water level, and the surplus water is zero.

Apart from the water diversion, another indicator for the best fit of the calculated and target values corresponds to a method for minimizing the difference between the controlled water level $H_{o}$ and the computed water level $H_{c}$ on the upstream mesh of the check. The function $J$ that evaluates the occurrence of surplus water $q_{y o s}$ is employed, where $q_{y o s}$ is the sum of surplus water at spillways.

Additionally, the sum of evaluation functions for the water diversion and water level, as shown in equation (7), and the sum of evaluation functions for the water level and surplus water, as shown in equation (8), may also be used as indicators.

$$
\begin{gathered}
J=\sum\left\{\left(q_{b o i}-q_{b c i}\right)^{2} / q_{b o i}+\left(H_{o i}-H_{c i}\right)^{2} / H_{o i}\right\} / N \\
J=\sum\left\{\left(q_{b o i}-q_{b c i}\right)^{2} / q_{b o i}+q_{y o s}\right\} / N
\end{gathered}
$$

In this study, the following four types of evaluation functions were used.

- Evaluation function 1: for the best fit of water diversion

- Evaluation function 2: for the best fit of water level

- Evaluation function 3: for the best fit of water diversion and water level.

- Evaluation function 4: for the best fit of water diversion and surplus water

\section{Penalty function}

To utilize the DFP method (Kadoya et al., 1980) to determine the optimal value of the inflow model coefficients, a penalty function $V$ was introduced to be added to the evaluation function to make the value of the evaluation function. The value of the evaluation function is set to a large value on outside the search range. In this study, the penalty function is defined as follows.

1. Model coefficients are non-negative

All coefficients in the inflow model are required to be nonnegative because there is no backflow.

$$
\begin{array}{ll}
\text { If } \alpha_{i} \geqq 0, & V_{i}=0 \\
\text { If } \alpha_{i}<0, & V_{i}=\left(\alpha_{i}-1.0\right)^{2} \\
V_{\mathrm{I}}=\Sigma V_{i} &
\end{array}
$$

By setting $V_{i}=\left(\alpha_{i}-1.0\right)^{2}$ when $\alpha_{i}<0$, the $V_{i}$ becomes 1.0 or greater, and is increased in conjunction with increment of $\alpha_{i}$, which makes correcting the search direction to the positive direction easier.

2. Model coefficients are preferred to be smaller than 1.0

If the inflow flow rate is the same as the branch flow rate, the coefficients for the water inflow model are 1.0. In this study, the penalty function was defined as follows such that the inflow rate had values less than branch flow rate as possible.

$$
\begin{array}{ll}
\text { If } \alpha_{i} \leqq 1, & V_{i}=0 \\
\text { If } \alpha_{i}>1, & V_{i}=\left(\alpha_{i}\right)^{2} \\
V_{\text {II }}=\Sigma V_{i} &
\end{array}
$$

3. Surplus water should not occur

The penalty function was defined as follows given that the occurrence of surplus water was desired to be avoided.

$$
V_{\mathrm{III}}=q_{\text {yos }} / \mathrm{N}
$$

4. Correction for evaluation function $J$

$$
\begin{aligned}
& \text { If } V_{\mathrm{I}}=V_{\mathrm{II}}=V_{\mathrm{III}}=0, \quad J=J_{\mathrm{p}} \\
& \text { If } V_{\mathrm{I}} \neq 0 \text { or } V_{\mathrm{II}} \neq 0 \text { or } V_{\mathrm{III}} \neq 0, \\
& J=J_{p-1}+V_{\mathrm{I}}+V_{\mathrm{II}}+V_{\mathrm{III}}
\end{aligned}
$$

$J_{p}$ is the newest value of the evaluation function obtained when all the constraints are satisfied, and $J_{p-1}$ is the value one step before $J_{p}$ is obtained. If the penalty function $\Sigma V$ is zero, then $J=J_{p}=J_{p-1}$. The initial value $J_{0}$ is given as zero.

\section{Powell's conjugate gradient method}

The unconstrained nonlinear optimization methods include the gradient method that uses the first-order differential of the function and Newton's method that utilizes the secondorder differential. When using either method, the differential coefficient must be calculated, although the gradient cannot be calculated in some cases. In Powell's method however, a differential coefficient is not required. 
The identification of a coefficient for a tank model, which is one of the methods used for runoff analysis, employs the DFP method, which is Powell's conjugate gradient method. In this study, the same approach was used to determine the optimal value for the inflow coefficient. The details concerning the algorithm of Powell's method used in this work can be found in the literature (Kadoya and Nagai, 1980).

\section{Water supply and diverged water from the main canal at Sakurakane}

\subsection{Problems in terms of water feed management}

The use of water agricultural waterways is characterized by the supply of agricultural water whose demand fluctuates considerably while water is diverged along the way; in addition, the amount of water received becomes less stable towards the downstream region and prone to water shortage. Furthermore, water flows slowly, and it takes time for the water to reach its destinations, which makes it difficult to feed water to adjust for the surplus and insufficiencies at the terminals of the waterway.

In an open channel system, the impact of water diversion from the upstream region is carried on to the downstream region, and the system takes a supply-oriented water management approach in which water diversion by users in the upstream area is prioritized and those who supply the water have the authority. Therefore, various water management issues arise as lesser amount of water is available the further it reaches to the terminal in this section. For instance, the water may fail to reach the downstream region if the upstream users consume more water than expected, and the slow flow of water in the open channel, which means that large time is required for the water to reach its destination, cannot effectively address the fluctuation in the demand at the terminal.

Since the designed flow rate of the side pipeline is $20-30 \%$ of the main open channel, which is equivalent to the flow rate for water demands in winter, the initial values of all coefficients are set to 0.2 in this paper.

The value of the water inflow factor $\alpha$ is searched in a direction smaller than 0.2 if $\alpha$ does not contribute much to the flow stability, and in a direction much larger than 0.2 if it contributes to the flow stability greatly. This implies that the search is performed from the given initial value toward the optimum value.

\subsection{Water supply and diverged water}

To address these problems by means of water delivery management, water is fed in advance while taking into account the demand volume and arrival of irrigation water to the terminals from Sakurakane. The values measured from July 6 to 7, 2014 for the water passing through the Sakurakane $\mathrm{CH}$ and diverged water flowing out of the main canal are available. Because this study aimed to systematically resolve the delay in the arrival of the water supply due to the doublewaterway, water flowing through the Sakurakane $\mathrm{CH}$ was defined as the cumulative flow of the water diversion, as shown in Figure 2, given that the water data from the Sakurakane $\mathrm{CH}$ was data obtained considering the flow boundary conditions at the upstream edge of the hydraulic computational model.

Table 3 presents the sum of water diversions in each check section. Figure 3 shows the changes in water diversion for the sections that correspond to the numbers assigned in the figure.

Table 3: Total water diversion by check section

\begin{tabular}{|c|c|c|c|c|}
\hline \multirow{2}{*}{$\frac{\text { Section }}{1}$} & \multicolumn{3}{|c|}{ Section Name } & \multirow{2}{*}{$\begin{array}{c}\text { Expected Volume } \\
\mathrm{m}^{3}\end{array}$} \\
\hline & Sakurakane $\mathrm{CH}$ & $\sim$ & Kitaike $\mathrm{CH}$ & \\
\hline 2 & Kitaike $\mathrm{CH}$ & $\sim$ & Handa $\mathrm{CH}$ & 24,149 \\
\hline 3 & Handa CH & $\sim$ & Naruiwa $\mathrm{CH}$ & 96,034 \\
\hline 4 & Naruiwa $\mathrm{CH}$ & $\sim$ & Itayama $\mathrm{CH}$ & 8,770 \\
\hline 5 & Itayama $\mathrm{CH}$ & $\sim$ & Hibara $\mathrm{CH}$ & 25,531 \\
\hline 6 & Hibara $\mathrm{CH}$ & $\sim$ & Owaki CH & 60,862 \\
\hline 7 & Owaki CH & $\sim$ & Unoike $\mathrm{CH}$ & 26,316 \\
\hline 8 & Unoike $\mathrm{CH}$ & $\sim$ & Sugakari CH & 15,120 \\
\hline 9 & Sugakari CH & $\sim$ & Kowa CH & 23,760 \\
\hline 10 & Kowa $\mathrm{CH}$ & $\sim$ & Utumi CH & 16,128 \\
\hline 11 & Utumi $\mathrm{CH}$ & $\sim$ & Mihama CH & 22,905 \\
\hline 12 & Mihama $\mathrm{CH}$ & $\sim$ & Terminal & 37,908 \\
\hline & & Tota & & 489,387 \\
\hline
\end{tabular}

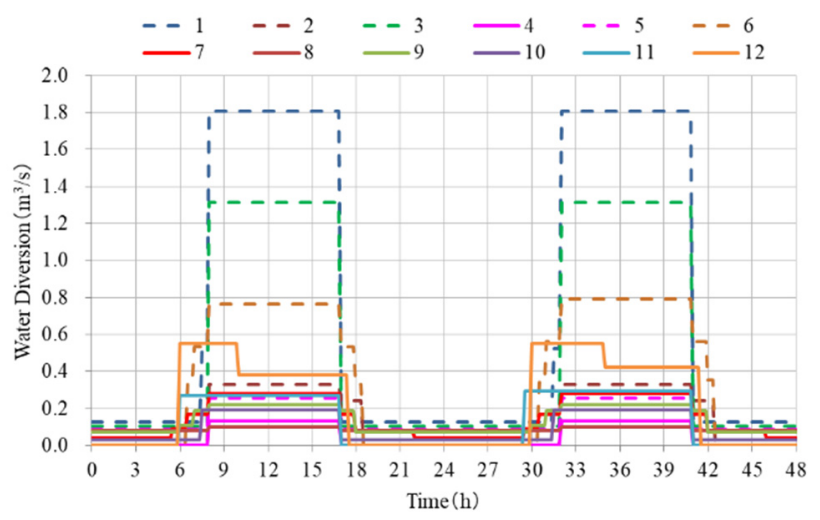

Figure 2: Water supply from Sakurakane

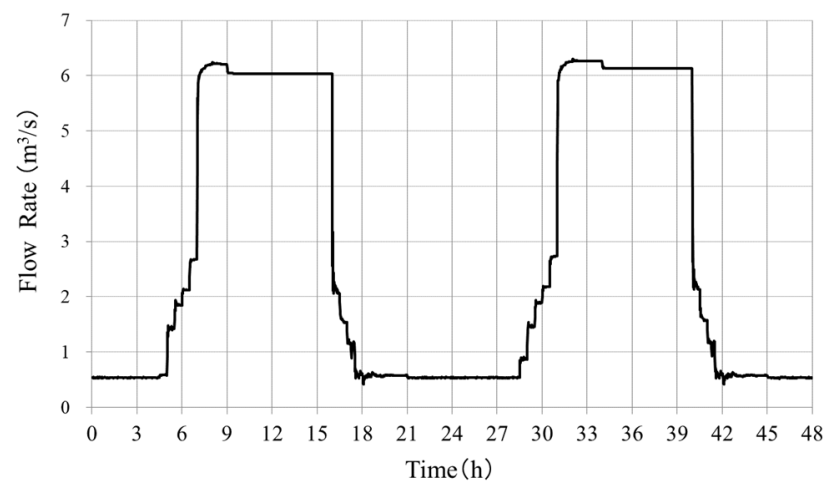

Figure 3: Changes in water diversion per check section

\section{Search for evaluation function values}

The criterion for evaluation is to minimize the value of the evaluation function. Figure 4 shows the search result for an evaluation function value over the process of the search for an optimal set of coefficients. The vertical axis shows the evaluation function value and the horizontal axis shows the number of hydraulic calculations performed by changing coefficients. 


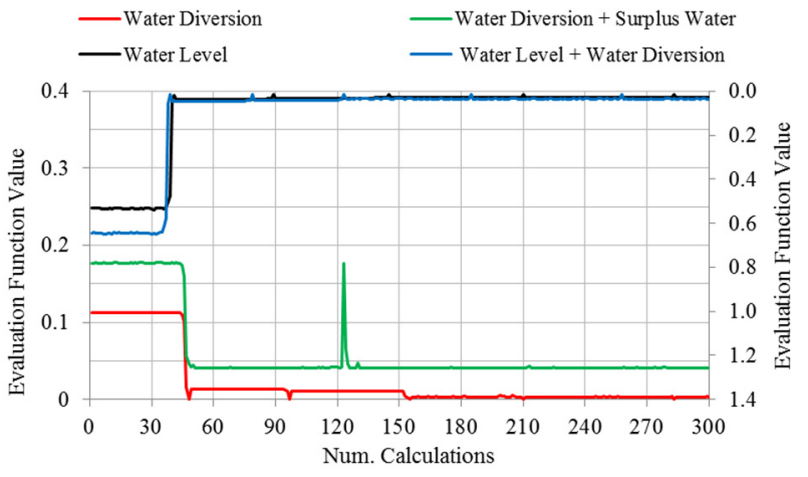

Figure 4: Search for evaluation function value

The minimum value for an evaluation function value was determined after 40-50 calculations, and a set of coefficients in which the value was minimized was attempted to be determined by further changing the coefficients. Because the penalty function is not zero even when the evaluation function reaches a combination that results in a zero value, the calculations in which the evaluation function was minimized along with the minimization of the penalty function were repeated. The calculations were stopped once the calculation step width reached zero, but a set of coefficients in which the penalty function becomes zero was not found.

\section{Search result for an evaluation function values}

\subsection{Combination of water diversion, water level, and sur- plus water}

Four types of evaluation functions were defined, which were labeled as Cases 1 through 4. To evaluate the difference in the volume of the inflow owing to the difference in the evaluation function, a search computation was repeated for each case to extract the set of coefficients in which the evaluation function and the insufficiency were minimized.

The ideal water delivery was considered to be a state in which the insufficiency and surplus are both zero while the maximum and total volume of inflow can be minimized.

The expected water diversion and actual water diversion, as well as the insufficiency, volume of surplus water in the overflow of the spillway, and water storage within the channel were organized for water delivery in which the extracted set of coefficients was used, as presented in Table 4 .

The volume in the waterway is the respective sum of the maximum and minimum values from each section $(11 \mathrm{sec}-$ tions). For the total volume of the inflow and water storage in the channel shown at the bottom of the table, the values for Case 1 were used as the baseline, and the changes in Cases 2 to 4 relative to the baseline are shown as values in white font in black cells.

The sections in between inflow points need to be maintained at the controlled water level of the check gate on the downstream side. Table 5 presents the difference between the controlled water level and the lowest water level at each of the check sections.

The results of the search for the evaluation function values indicated the following:
- Insufficiency did not occur in any of the four types of evaluation functions.

- Surplus water occurred for all of the evaluation functions.

- The volume of inflow and surplus water varied across all evaluation functions in terms of both the maximum and total volumes.

- The volume of inflow and surplus water were minimized in terms of both the maximum and total volumes in Case 4, in which the water diversion and surplus water were used as evaluation functions.

- In Case 4, the lowest water level at the OwakiSugakari section and the terminal section dropped to the controlled water level of $0.5 \mathrm{~m}$; however, whether this can be allowed must be further considered.

- The second smallest result was observed for Case 3, in which the water diversion and water level were used as evaluation functions.

- Owing to the differences in evaluation functions, occurrences of the inflow and surplus water varied to some extent.

- The evaluation confirmed that an unacceptable drop in the water level occurred in cases in which the best fit of the water level was not evaluated.

Given that the insufficiencies, volume of inflow, and surplus water were generally small, the reduction in the water level in each section was also small, and because the final volume of water in the waterway was relatively large, the evaluation function pertaining to the best fit of water diversion and water level from Case 3 was judged to be appropriate as the optimal evaluation function.

\subsection{Case when inflow facilities that has small contribution to stabilize the flow in main channel is not used}

Reducing the number of water inflow facilities is a merit in terms of costs for construction and operation.

Water inflow facilities that do not contributes much to stabilize the flow in main channel are not needed, as long as the water level necessary for diversion can be secured in the downstream of the main open channel.

In Case 3, which uses an evaluation function related to the degree of water diversion and water level adaptability, the volume of water inflow from Kitaike to Owaki $\mathrm{CH}$ is considerably small in terms of time and quantity.

Therefore, Case 5 was studied in which the number of water inflow points was reduced from 10 locations to 5 locations downstream from Unoike $\mathrm{CH}$ to the terminal point. The results are shown in Table 4.

As a result, the deficit volume and water inflow volume can be suppressed to the same extent as in Case 3 even if the inflow points were reduced to five locations, implying that the water injection point may be reduced.

\section{Water delivery and inflow by considering differences in evaluation function}

Out of the searched coefficients, water delivery by the main canal and inflow from the inlet in the case in which inflow takes place under the combination of coefficients in 
Table 4: Coefficient extracted from the search result for an evaluation function, water delivery, and inflow

\begin{tabular}{|c|c|c|c|c|c|c|c|}
\hline & Case & & Case 1 & Case 2 & Case 3 & Case 4 & Case 5 \\
\hline Evaluati & on Function & & $\begin{array}{c}\text { Water } \\
\text { Diversion }\end{array}$ & Water Level & $\begin{array}{c}\text { Water } \\
\text { Diversion+ } \\
\text { Water Level }\end{array}$ & $\begin{array}{c}\text { Water } \\
\text { Level+ } \\
\text { Surplus } \\
\text { Water } \\
\end{array}$ & $\begin{array}{c}\text { Water } \\
\text { Diversion+ } \\
\text { Water Level }\end{array}$ \\
\hline & $\alpha_{1}$ & Kitaike $\mathrm{CH}$ & 0.000 & 0.000 & 0.000 & 0.000 & - \\
\hline & $\alpha_{2}$ & Handa CH & 0.234 & 0.014 & 0.114 & 0.221 & - \\
\hline & $\alpha_{3}$ & Naruiwa $\mathrm{CH}$ & 0.236 & 0.328 & 0.206 & 0.284 & - \\
\hline & $\alpha_{4}$ & Itayama $\mathrm{CH}$ & 0.343 & 0.040 & 0.181 & 0.217 & - \\
\hline & $\alpha_{5}$ & Hibara $\mathrm{CH}$ & 0.232 & 0.110 & 0.145 & 0.217 & - \\
\hline Coefficient & $\alpha_{6}$ & Owaki CH & 0.228 & 0.161 & 0.009 & 0.219 & - \\
\hline & $\alpha_{7}$ & Unoike $\mathrm{CH}$ & 0.231 & 0.179 & 0.680 & 0.217 & 0.680 \\
\hline & $\alpha_{8}$ & Sugakari $\mathrm{CH}$ & 0.232 & 2.523 & 1.162 & 0.217 & 1.162 \\
\hline & $\alpha_{9}$ & Kowa CH & 2.277 & 2.041 & 1.162 & 0.905 & 1.162 \\
\hline & $\alpha_{10}$ & Utumi CH & 1.998 & 2.597 & 1.163 & 0.904 & 1.163 \\
\hline & $\alpha_{11}$ & Terminal & 1.428 & 1.398 & 1.164 & 0.894 & 1.164 \\
\hline & Kitaike $\mathrm{CH}$ & $\mathrm{m}^{3} / \mathrm{s}$ & 0.000 & 0.000 & 0.000 & 0.000 & - \\
\hline & Handa CH & $\mathrm{m}^{3} / \mathrm{s}$ & 0.078 & 0.005 & 0.038 & 0.073 & - \\
\hline & Naruiwa $\mathrm{CH}$ & $\mathrm{m}^{3} / \mathrm{s}$ & 0.310 & 0.431 & 0.270 & 0.373 & - \\
\hline & Itayama CH & $\mathrm{m}^{3} / \mathrm{s}$ & 0.001 & 0.000 & 0.000 & 0.000 & - \\
\hline & Hibara CH & $\mathrm{m}^{3} / \mathrm{s}$ & 0.019 & 0.009 & 0.012 & 0.018 & - \\
\hline Max. Inflow & Owaki $\mathrm{CH}$ & $\mathrm{m}^{3} / \mathrm{s}$ & 0.181 & 0.127 & 0.007 & 0.173 & - \\
\hline & Unoike $\mathrm{CH}$ & $\mathrm{m}^{3} / \mathrm{s}$ & 0.060 & 0.046 & 0.177 & 0.037 & 0.177 \\
\hline & Sugakari CH & $\mathrm{m}^{3} / \mathrm{s}$ & 0.025 & 0.222 & 0.128 & 0.015 & 0.128 \\
\hline & Kowa CH & $\mathrm{m}^{3} / \mathrm{s}$ & 0.402 & 0.406 & 0.267 & 0.208 & 0.267 \\
\hline & Utumi CH & $\mathrm{m}^{3} / \mathrm{s}$ & 0.329 & 0.329 & 0.221 & 0.172 & 0.221 \\
\hline & Terminal & $\mathrm{m}^{3} / \mathrm{s}$ & 1.206 & 1.182 & 0.984 & 0.756 & 0.984 \\
\hline Total Inflow & Maximum & $\mathrm{m}^{3} / \mathrm{s}$ & 1.850 & -0.028 & -0.351 & -0.541 & -0.151 \\
\hline I otal Intlow & Total & $\mathrm{m}^{3}$ & 26430 & 1490 & 13 & -3352 & -1181 \\
\hline Water Diversion & Expected & $\mathrm{m}^{3}$ & 489,387 & 0 & 0 & 0 & 0 \\
\hline water Diversion & Actual & $\mathrm{m}^{3}$ & 489,387 & 0 & 0 & 0 & 0 \\
\hline Insufficiency & & $\mathrm{m}^{3}$ & 0 & 0 & 0 & 0 & 0 \\
\hline Surnlus Water & Maximum & $\mathrm{m}^{3} / \mathrm{s}$ & 0.928 & -0.013 & 0.036 & -0.025 & -0.023 \\
\hline surpius water & Total & $\mathrm{m}^{3}$ & 8,012 & -58 & -371 & -1223 & -557 \\
\hline & Initial & $\mathrm{m}^{3}$ & 135,332 & 0 & 0 & 0 & 0 \\
\hline & Final & $\mathrm{m}^{3}$ & 127,660 & 55 & 316 & 1090 & 484 \\
\hline Storage & Used (Initial-Final) & $\mathrm{m}^{3}$ & 7,672 & -55 & -316 & -1090 & -484 \\
\hline storage & Maximum & $\mathrm{m}^{3}$ & 166,368 & -189 & -1332 & -871 & -10695 \\
\hline & Minimum & $\mathrm{m}^{3}$ & 116,993 & 1463 & 2784 & 1375 & 11145 \\
\hline & Used (Max-Min) & $\mathrm{m}^{3}$ & 49,375 & -1652 & -4116 & -2246 & -21840 \\
\hline
\end{tabular}

which the evaluation function is minimized was considered.

The water flow passing through the Sakurakane $\mathrm{CH}$ was distributed into a water passage that flowed down the open channel and the water inflow from the inlet via the adjacent bypass pipeline at the point of diversion. This is shown in Figures 5-8.

In Case 1, the maximum flow that diverged to the adjoining channel was $1.85 \mathrm{~m}^{3} / \mathrm{s}$ compared to the maximum water flow of $6.206 \mathrm{~m}^{3} / \mathrm{s}$ through the Sakurakane $\mathrm{CH}$, which confirmed that a maximum of approximately $30 \%$ of the water was delivered to the inflow point to achieve appropriate water delivery management. The flow in the main canal and adjoining channel stabilized in the order of Case $1<$ Case $2<$ Case $3<$ Case 4 , which also corresponded to the order of decrease in the total maximum water inflow volume for all water inflow works. 
Surplus water occurred at the Mihama $\mathrm{CH}$, located at the terminal, after an increase or decrease in the flow in the main canal and volume of water diversion. The results for Cases 1-4 are shown in Figures 9 and 10. The smallest value for both the maximum value and total amount was observed for Case 4, in which the evaluation function included the surplus water.

Figure 11 shows the results pertaining to Case 3, which pertains to the volume of inflow in each section. The inflow

Table 5: Deviation from controlled water level due to differences in evaluation functions

\begin{tabular}{|c|c|c|c|c|c|}
\hline \multicolumn{2}{|c|}{ Case } & Case 1 & Case 2 & Case 3 & Case 4 \\
\hline \multirow[b]{2}{*}{ Check } & \multirow[b]{2}{*}{$\begin{array}{l}\text { Controlled Water } \\
\text { Level (TP.m) }\end{array}$} & \multicolumn{4}{|c|}{ Evaluation Function } \\
\hline & & $\begin{array}{l}\text { Water } \\
\text { Diversion }\end{array}$ & Water Level & $\begin{array}{c}\text { Water } \\
\text { Diversion+ } \\
\text { Water Level }\end{array}$ & $\begin{array}{l}\text { Water Level+ } \\
\text { Surplus Water }\end{array}$ \\
\hline \multicolumn{6}{|l|}{ Sakurakane } \\
\hline & 31.431 & -0.216 & -0.179 & -0.164 & -0.102 \\
\hline \multicolumn{6}{|l|}{ Kitaike $\mathrm{CH}$} \\
\hline & 30.974 & -0.192 & -0.206 & -0.197 & -0.171 \\
\hline \multicolumn{6}{|l|}{ Handa $\mathrm{CH}$} \\
\hline & 29.993 & -0.252 & -0.249 & -0.252 & -0.219 \\
\hline \multicolumn{6}{|l|}{ Naruiwa $\mathrm{CH}$} \\
\hline & 28.983 & -0.07 & -0.073 & -0.07 & -0.07 \\
\hline \multicolumn{6}{|l|}{ Itayama $\mathrm{CH}$} \\
\hline & 28.154 & -0.199 & -0.243 & -0.267 & -0.198 \\
\hline \multicolumn{6}{|l|}{ Hibara $\mathrm{CH}$} \\
\hline & 27.172 & -0.213 & -0.218 & -0.228 & -0.213 \\
\hline \multicolumn{6}{|l|}{ Owaki CH } \\
\hline & 26.022 & -0.214 & -0.247 & -0.143 & -0.216 \\
\hline \multicolumn{6}{|l|}{ Unoike $\mathrm{CH}$} \\
\hline & 25.479 & -0.451 & -0.077 & -0.077 & -0.455 \\
\hline \multicolumn{6}{|l|}{ Sugakari $\mathrm{CH}$} \\
\hline & 24.486 & -0.018 & -0.02 & -0.027 & -0.029 \\
\hline \multicolumn{6}{|l|}{ Kowa CH } \\
\hline & 23.997 & -0.007 & -0.007 & -0.008 & -0.015 \\
\hline \multicolumn{6}{|l|}{ Utumi $\mathrm{CH}$} \\
\hline Mihama spillway & 23.450 & -0.186 & -0.268 & -0.206 & -0.541 \\
\hline Terminal & & & & & \\
\hline
\end{tabular}

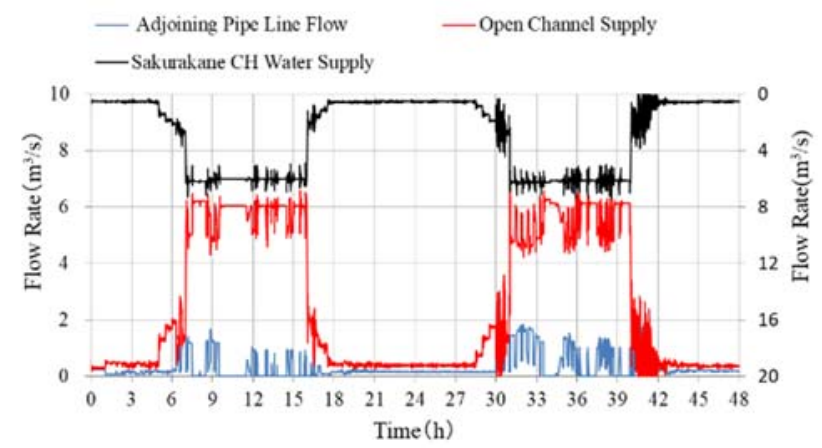

Figure 5: Water supply in Case 1 (water diversion)

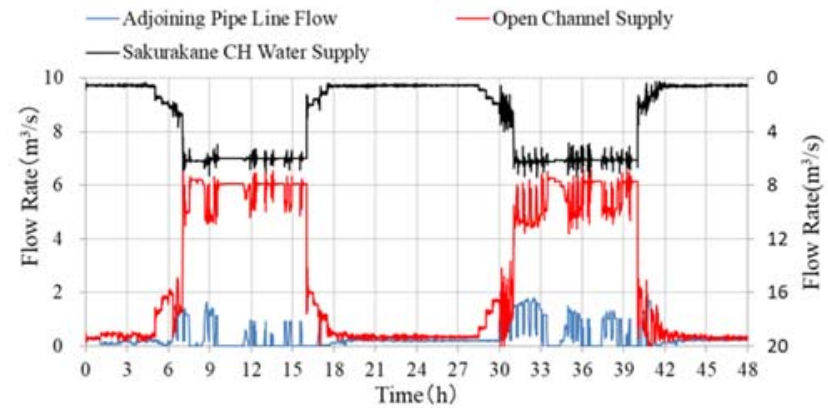

Figure 6: Water supply in Case 2 (water level) was smaller in terms of both the time and volume at the upstream Owaki $\mathrm{CH}$ section, because the water level did not tend to decrease and shortage of water supply did not occur in the upstream area of the main channel, at which the water supply could be accessed in priority under a water delivery management strategy that favored the upstream region.

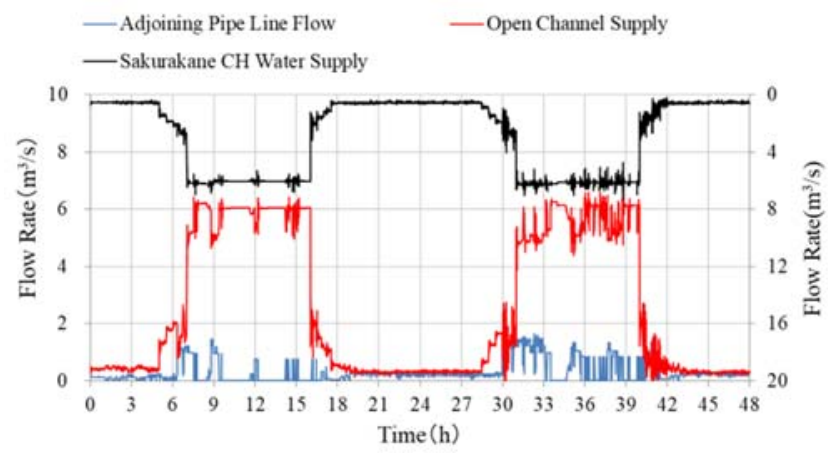

Figure 7: Water supply in Case 3 (water level + water diversion)

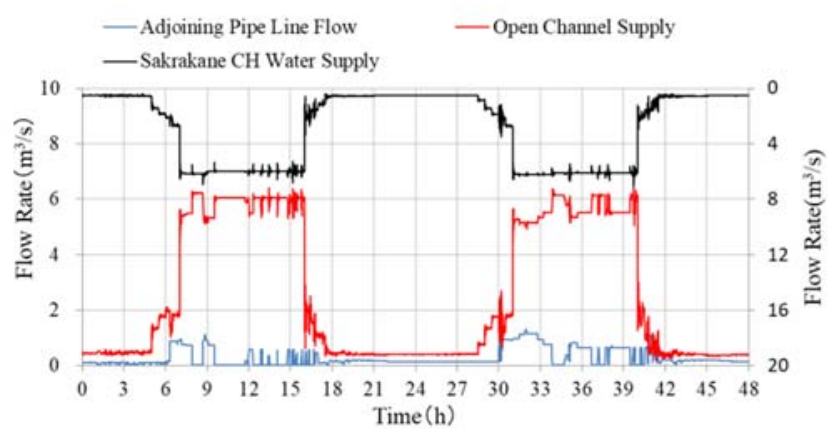

Figure 8: Water supply in Case 4 (water level + surplus water)

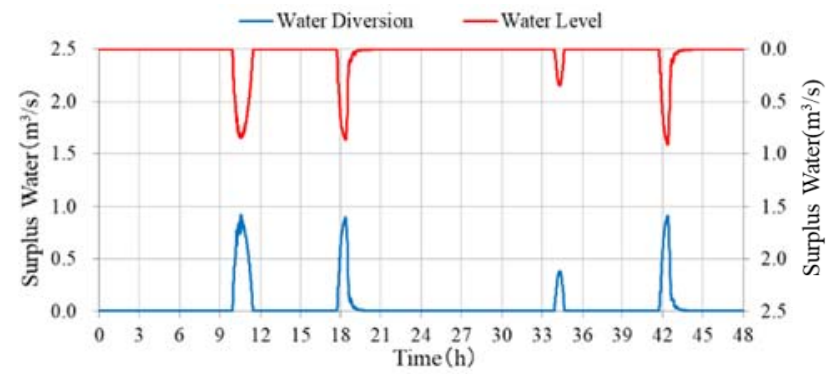

Figure 9: Surplus water in Cases 1 and 2 (Mihama)

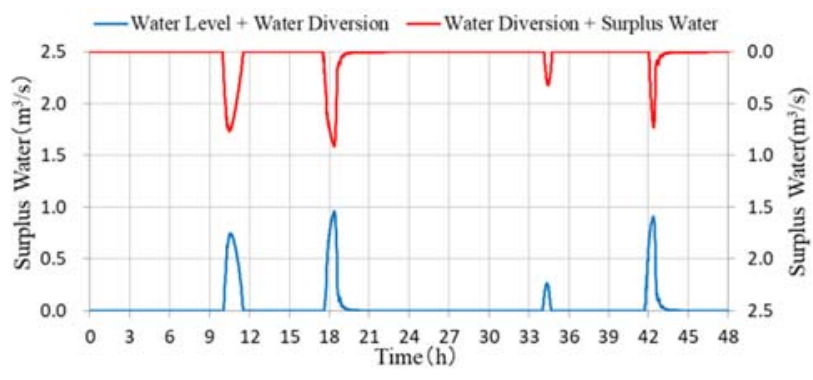

Figure 10: Surplus water in Cases 3 and 4 (Mihama) 

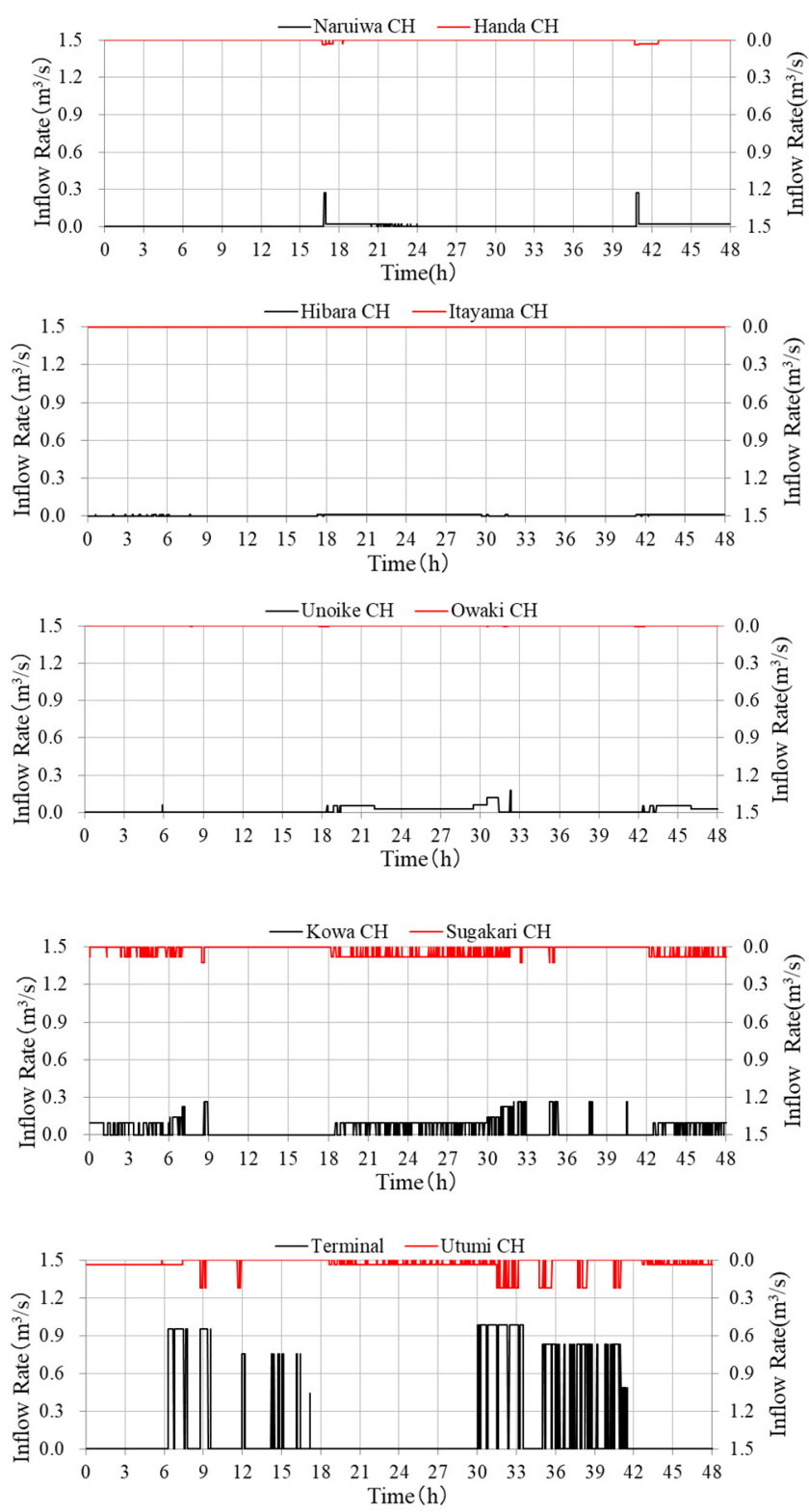

Figure 11: Volume of inflow in Case 3 (water level + water diversion)
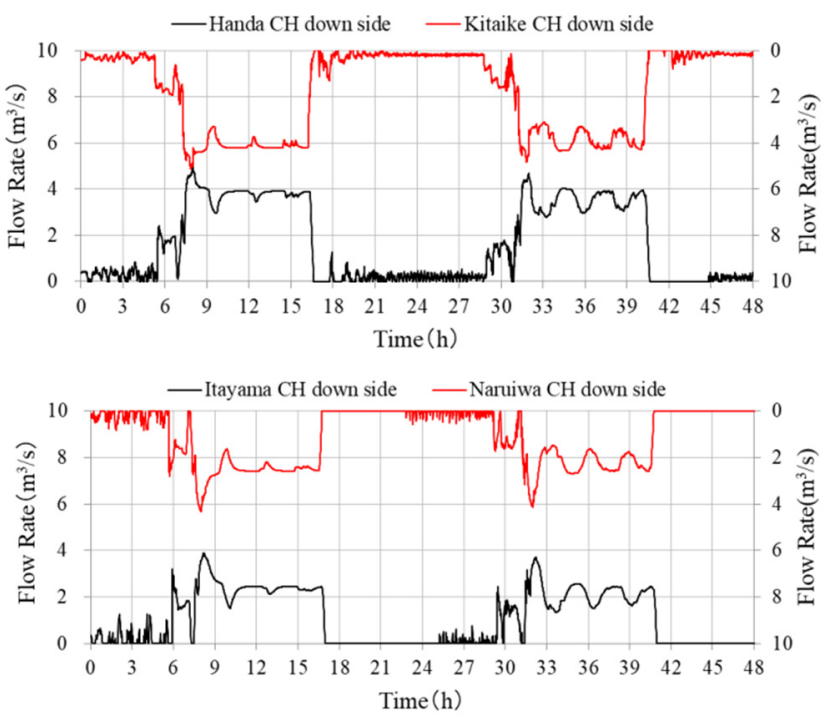
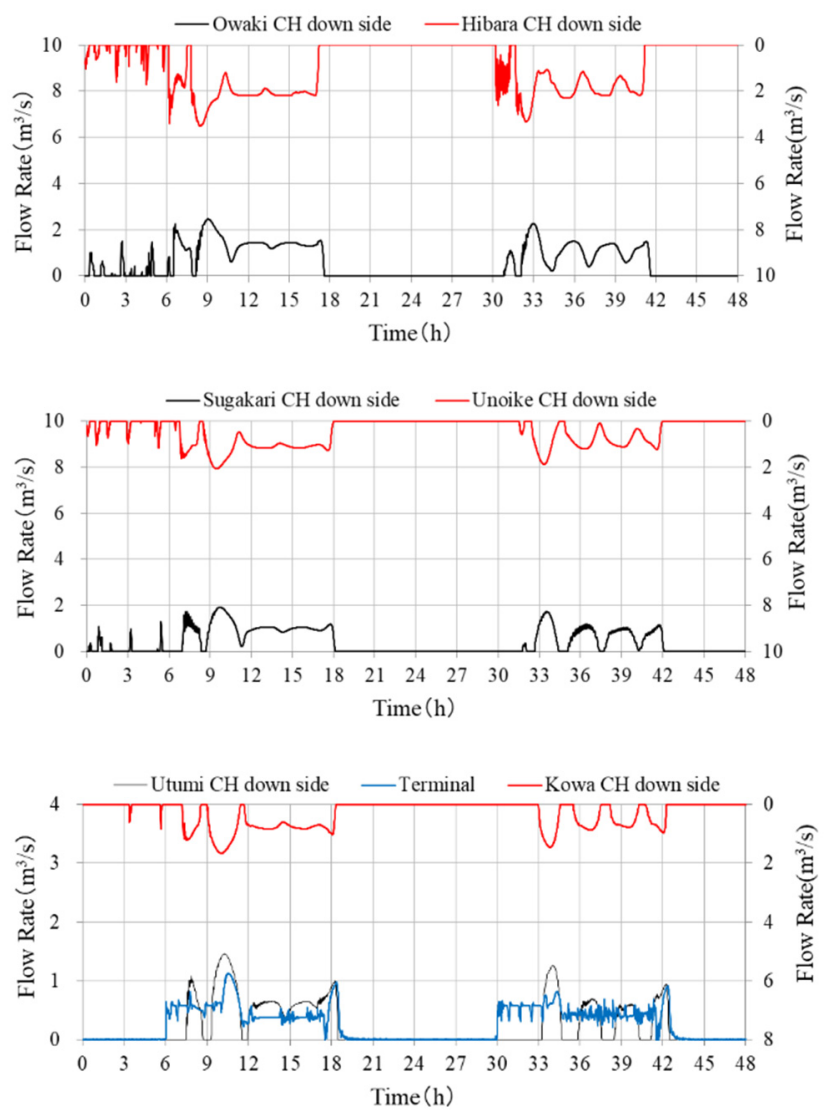

Figure 12: Changes in flow in Case 3 (water level + water diversion)

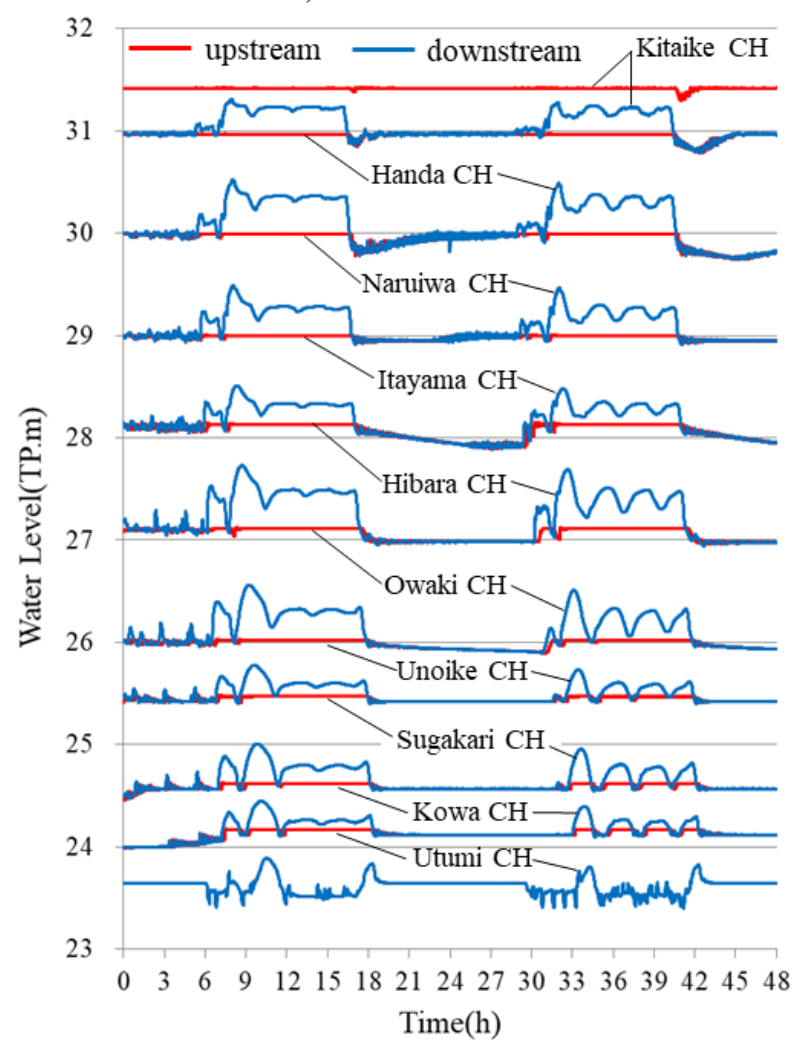

Figure13: Changes in water level in Case 3 (water level + water diversion) 


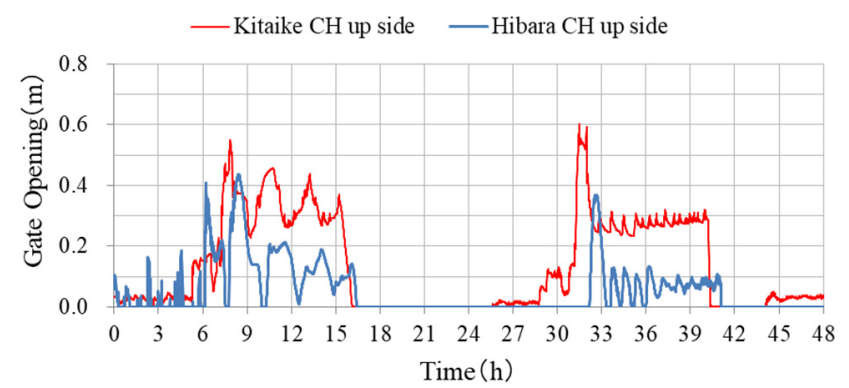

Figure 14: Changes in gate opening in Case 3 (water level + water diversion)

\section{Flow curve of the main channel during an inflow}

Figures 12 and 13 show the flow rate and water level at both the upstream and downstream regions of the check gate for Case 3 , in which the water diversion and water level were used as the evaluation functions. The upstream area from the Kitaike $\mathrm{CH}$ to the Hibara $\mathrm{CH}$ continued to fluctuate in terms of water level and flow, even when there was barely any inflow.

The downstream area beyond the Owaki $\mathrm{CH}$ was affected by fluctuation in the water supplied from the upstream and the volume of inflow, and repeated increase and decrease, respectively, in terms of the water level and flow were noted.

Furthermore, a flow pertaining to the main open channel was formed by an inflow of the bypass pipeline when the supply from the main canal did not reach the terminal. Additionally, the water level of the main open channel fluctuated slightly in a short period of time due to an intermittent increase and decrease in the volume of inflow by bypass pipeline.

The AMIL gate is known for its characteristic in which the behavior becomes unstable at times other than those involving the design flow (Takeda and Inagaki, 2019). Figure 14 shows the degree of opening of the AMIL check gate; the gate exhibits repeated opening and closing behavior.

The changes in the flow in the adjoining bypass pipeline due to an inflow manifest in the form of fluctuation of flow in the main open channel, and this impact leads to the occurrence of the hunting phenomenon wherein the gate opens and closes repeatedly

\section{Conclusion}

It was assumed that a bypass pipeline was constructed alongside a long main open channel in an agricultural section located downstream of the Aichi waterway.

An optimal combination of the position of inflow and volume of inflow from a pipeline into the main open channel was attempted to be determined by embedding a conjugate gradient method called the DFP method into an unsteady flow program for an open channel in a double-channel system.

The key results of this investigation can be summarized as follows:

1. By ensuring flow into the main open channel from an inflow point on an adjoining bypass pipeline, an adequate water level can be secured for the downstream area of the main open channel, and an appropriate water delivery scheme can be implemented.

2. The optimal value for the evaluation function was attempted to be determined by combining the aspects of water diversion, water level, and surplus water. A favorable result was obtained by combining water diversion and water level. In this case, the insufficiency in the amount of water, volume of inflow, and surplus water were generally small. Furthermore, the degree of reduction in the water level in each section was minimal, and the final value of the water volume in the channel was relatively large and are considered as the optimal solutions.

3. If an evaluation function combining the water level and the water diversion is adopted, the six water inflow points with a small contribution to the flow stability are not used, may be reduced.

4. When an AMIL gate of the main open channel was used to double-waterway by adjoining bypass pipeline, the changes in the flow in the adjoining channel due to the inflow appeared as a change in the flow in the main canal, consequently leading to a hunting phenomenon in which the check gate repeatedly opened and closed, which ultimately destabilized the flow.

5. The double-waterway system is an ideal system in which the open channel and the pipeline mutually overcome the limitations of each other, and the system is capable of managing the demand fluctuation at the terminals.

\section{References}

[1] Kadoya, M., and Nagai, A. (1980): Outflow Analysis Method (Part 11)- Optimal Identification of Reservoir Function by SDFP Method-, Jour. JSIDRE, 48 (11), pp. 65-70, (in Japanese).

[2] Shiraishi, H. (1969): Unsteady Flow Analysis in a Rectangular Cross Section Channel, Agriculture and forestry research center report, A4, pp.217-225, (in Japanese).

[3] Takeda, N., and Inagaki, H. (2018): Water Supply Management Combining Level-Reactive Type and Flow Rate-Reactive Type Upstream and Downstream Water Level Control Gates, Journal of Rainwater Catchment Systems, 23(2), pp.43-52, (in Japanese).

[4] Takeda, N., and Inagaki, H. (2019): Technical Problem of Water Supply Management caused by Diurnal Demand Fluctuations in Long-Distance Open Channel, Journal of Rainwater Catchment Systems, 24(2), pp.33-44, (in Japanese). 